\title{
PENGAJARAN SHALAT FARDHU MELALUI MODEL PEMBELAJARAN PICTURE AND PICTURE UNTUK MENINGKATKAN HASIL BELAJAR PADA SISWA KELAS III SEMESTER GANJIL SDN 011 BALIKPAPAN TIMUR TAHUN PELAJARAN 2019/2020
}

\author{
MAHFIAH \\ KEMENTERIAN AGAMA KOTA BALIKPAPAN \\ E-mail : mahfiahmahfia721@gmail.com
}

\begin{abstract}
ABSTRAK
Penelitian perbaikan pembelajaran ini dilaksanakan sebanyak dua siklus setiap siklus dilakukan tes tiap akhir pertemuan. Subyek penelitian ini adalah siswa kelas III berjumlah 29 siswa dan obyek penelitian ini adalah model pembelajaran picture and picture.Teknik pengumpulan data yang digunakan adalah teknik dokumentasi untuk mengetahui nilai dasar dan pengelompokan siswa, observasi untuk mengetahui aktivitas siswa dan guru, teknik tes untuk mengetahui nilai rata-rata dan ketuntasan belajar siswa. Penelitian dilakukan sebanyak dua siklus teknik analisis data menggunakan statistik deskriptif berupa rata-rata, presentase dan grafik. Yang bertindak sebagai pelaksana dalam pembelajaran adalah peneliti, dan observator nya dalah teman sejawat yang merupakan guru senior dari kelas III. Hasil analisis data menunjukkan bahwa terjadi terjadi peningkatan hasil belajar tentang Shalat Fardhu kelas III SDN 011 Balikpapan Timur. Hal tersebut tampak pada peningkatan hasil belajar siswa pada setiap siklus. yaitu yaitu dari pra siklus dengan rata-rata 66,35 meningkat menjadi 71,03 pada siklus I kemudian pada siklus II nilai rata-rata hasil belajar siswa meningkat menjadi 83,34 , begitupun persentase ketuntasan belajar meningkat dari pra siklus yang hanya $45 \%$ menjadi $62 \%$ pada siklus I, kemudian siklus II menjadi $90 \%$ siswa. Dengan demikian dapat disimpulkan bahwa Model pembelajaran picture and picture dapat meningkatkan hasil belajar tentang shalat fardhu pada siswa kelas III SDN 011 Balikpapan Timur Tahun Pelajaran 2019/2020 Pengajaran Shalat Fardhu Melalui Model Pembelajaran Picture and Picture untuk Meningkatkan Hasil Belajar pada Siswa Kelas III Semester Ganjil SDN 011 Balikpapan Timur Tahun Pelajaran 2019/2020
\end{abstract}

Kata Kunci: Shalat Fardhu , Peningkatan Hasil Belajar, Model pembelajaran picture and picture

\section{PENDAHULUAN}

Manusia diciptakan oleh Allah SWT, untuk beribadah kepada-Nya secara ikhlas. Salah satu bentuk ibadah adalah shalat yang merupakan salah satu rukun Islam. Perintah ibadah shalat diterima oleh Nabi Muhammad SAW, secara langsung dari Allah SWT diwaktu mi'raj melalui Malaikat Jibril. Kedudukan ibadah shalat sangat penting bagi kehidupan manusia sehingga disebut tiang agama, bahkan ibadah shalat itulah yang pertama dihisab dihari kiamat kelak.1 Sesuai dengan sabda Nabi Muhammad SAW yang berbunyi:

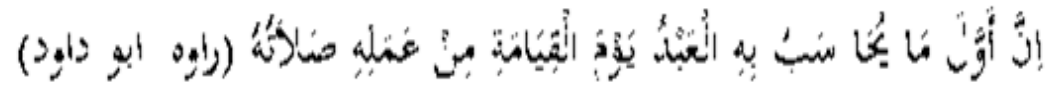

IArtinya: Amal seorang hamba yang pertama kali dihisab pada hari kiamat adalah shalatnya. (HR. Abu Daud). Hadits di atas menjelaskan bahwa amalan yang pertama kali dihisab (ditanya dan diminta pertanggung jawaban) dari segenab amalan seorang hamba dihari kiamat kelak adalah shalatnya. Bila shalatnya baik maka beruntunglah ia dan bilamana shalatnya rusak, sungguh kerugian menimpanya.Dalam agama Islam ada lima sendi ajaran yang harus dilaksanakan. Sendi-sendi itu bagaikan tiang rumah yang saling menunjang antara yang satu dengan yang lainya, apabila salah satu di antara tiang itu roboh maka akan roboh pula yang lainya. Kelima sendi Islam yang dimaksud adalah syahadat, 
shalat, zakat, puasa dan haji. Karena kelima hal tersebut merupakan sendi agama, maka kiranya sebagai umat Islam wajib memahami dan mengerti seperti halnya tentang shalat fardhu. karena shalat adalah perintah Allah SWT yang wajib dikerjakan, sebagaimana firman Allah SWT dalam Al- Qur'an surat Al- Baqarah: 43 yang berbunyi :

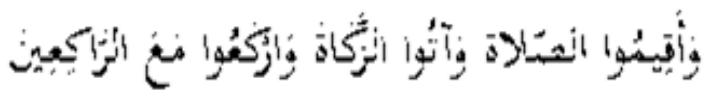

Artinya: Dan dirikanlah shalat, tunaikanlah zakat dan rukuklah beserta orang-orang yang rukuk. (QS. Al-Baqarah: 43). Mengingat demikian pentingnya fungsi shalat dalam kehidupan manusia, untuk membiasakan anak shalat, maka wajib bagi orang tua untuk memerintahkan anaknya yang masih kecil untuk melaksanakan shalat. Karena semakin sering anak SD kelas III mendapatkan stimulus pemahaman gerakan shalat yang diiringi dengan pengarahan tentang bagaimana gerakan shalat yang benar secara berulang-ulang maka anak semakin cepat hafal bacaan shalat tersebut. Hal ini diharapkan ketika anak sudah mencapai usia 10 tahun dan diperintah shalat mereka akan mengerjakan shalat dengan benar.

Dalam hal ini anak dibimbing untuk tunduk dan mengabdikan diri hanya kepada Allah, sesuai dengan fitrahnya. Kemudian sebagai pembuktian dari pengabdian itu, direalisasikan dalam bentuk perbuatan dan aktivitas yang bermanfaat sesuai dengan perintahnya. Memperhatikan begitu pentingnya kedudukan shalat dalam kehidupan manusia, maka pembiasaan pelaksanaan shalat terutama shalat fardhu sangat perlu diajarkan dan ditanamkan sejak dini ke dalam kehidupan manusia. Dengan demikian tingkat pemahaman anak terhadap materi shalat harus menjadi prioritas di antara materi pelajaran yang lain. Penggunaan metode yang tidak sesuai dengan tujuan pengajaran akan menjadi kendala dalam mencapai tujuan yang telah dirumuskan.Maka dari itu guru harus mampu menentukan metode yang tepat dalam menyampaikan materi shalat fardhu.Untuk mewujudkan tujuan pembelajaran materi shalat fardhu tersebut membutuhkan proses pembelajaran yang panjang.

Dalam proses belajar mengajar akan terjadi interaksi antara siswa dan guru. Suasana belajar sangat berpengaruh dalam meningkatkan kualitas belajar-mengajar, apabila pembelajaran menyenangkan dapat menimbulkan minat dan meningkatkan hasil belajar. Dalam hal ini guru harus dapat memfasilitasi siswa agar dapat meningkatkan potensi yang dimiliki oleh siswa dan membuat siswa aktif dalam belajar sehingga dapat mencapai hasil yang maksimal. Hasil belajar yang diinginkan tentu yang maksimal, untuk itu ada beberapa hal yang perlu diperhatikan oleh guru, salah satu di antaranya yang menurut penulis penting adalah penggunaan metode belajar. Karena metode belajar menjadi sarana yang membuat materi pelajaran lebih bermakna, yang tersusun dalam kurikulum pendidikan sedemikian rupa sehingga dapat dipahami atau diserap oleh siswa menjadi pengertian-pengertian yang fungsional terhadap tingkah lakunya.

Tanpa metode suatu materi pelajaran tidak akan dapat berproses secara efektif dan efisien dalam kegiatan belajar-mengajar menuju tujuan pendidikan. Untuk menciptakan situasi dan kondisi pembelajaran yang menyenangkan, dan dapat meningkatkan hasil belajar siswa terhadap materi shalat fardhu serta mempertimbangkan bagaimana caranya agar peserta didik dapat mengerti tentang materi yang akan disampaikan, maka diperlukan metode belajar yang sangat tepat. Metode belajar tersebut adalah metode Picture and picture. Metode picture and picture adalah suatu metode belajar yang menggunakan gambar dan dipasangkan/diurutkan menjadi urutan logis. Jadi dengan pembelajaran menggunakan gambar akan membuat pembelajaran menjadi nyata karena siswa dapat memperagakan langsung mengurutkan suatu proses yang berkenaan dengan materi shalat. dengan menggunakan gambar belajar akan lebih menarik dan menyenangkan.

Jadi metode picture and picture adalah metode belajar yang melatih siswa berfikir logis dan sistematis dengan menggunakan gambar sebagai media penyampaian materi pembelajaran sehinngga proses belajar menjadi lebih menarik dan dapat 
meningkatkan hasil belajar. Salah satu model pembelajaran yang memiliki ciri inovatif, aktif, kreatif, dan menyenangkan adalah model Picture and Picture. Model Picture and Picture merupakan suatu metode belajar yang menggunakan gambar yang dipasangkan atau diurutkan menjadi urutan logis (Hamdani, 2011: 89). Model Picture and Picture mengandalkan gambar sebagai media dalam proses pembelajaran. Suyatno (2004: 81) menyatakan bahwa penggunaan model pembelajaran picture and picture dalam pembelajaran shalat fardhu bertujuan agar siswa dapat shalat fardhu dengan cepat dan tepat. Model pembelajaran picture and picture dapat merangsang siswa agar lebih termotivasi dan tertarik dalam pembelajaran. Siswa dapat melihat secara langsung gambar yang akan dideskripsikan, sehingga siswa memperoleh kemudahan dalam kegiatan shalat fardhu .

Suprijono (2009: 125) mengemukakan langkah-langkah pembelajaran Picture and Picture, yaitu: guru menyampaikan kompetensi yang ingin dicapai, guru menyajikan materi sebagai pengantar, guru menunjukkan/memperlihatkan gambar-gambar yang berkaitan dengan materi, guru menunjuk/memanggil siswa secara bergantian memasang/mengurutkan gambar-gambar menjadi urutan yang logis, guru menanyakan alasan/dasar pemikiran urutan gambar tersebut, guru memulai menanamkan konsep/materi sesuai dengan kompetensi yang ingin dicapai, kesimpulan/rangkuman.

Berdasarkan hasil pengamatan awal diperoleh hasil ingkat keberhasilan siswa dalam menguasai materi pelajaran, terutama materi shalat fardhu nilai hasil belajar siswa masih rendah, disebabkan proses pembelajaran yang kurang efektif. Sehingga siswa banyak yang belum mampu mengucapkan niat shalat, bacaan dalam shalat dan gerakan dalam shalat. Siswa yang mampu mengucapkan niat shalat hanya mencapai $15 \%$, siswa yang mampu menyebutkan syarat sah shalat dan rukun shalat 10\%, dan siswa yang mampu melakukan gerakan dalam shalat fardhu hanya 10\% dari jumlah 23 Perolehan nilai rata-rata kelas yang seharusnya mencapai angka di atas 78, pada kenyatannya hanya mencapai angka 65, sehingga hanya 25\% siswa yang memenuhi Kriteria Ketuntasan Minimal (KKM) PAI untuk kelas III Semester II SDN 011 Balikpapan Timur Tahun Pelajaran 2019/2020

Dengan permasalahan yang telah diuraikan di atas, maka guru harus mengambil tindakan, yakni dengan mencari dan menggunakan suatu pendekatan atau model pembelajaran yang efektif, inovatif, dan berpotensi memperbaiki pembelajaran shalat fardu, sehingga meningkatkan minat, motivasi, dan sikap siswa terhadap pembelajaran yang berakibat pada meningkatnya prestasi belajar siswa. Dengan demikian guru dapat merancang suatu bentuk pembelajaran yang aktif, kreatif, efektif, dan menyenangkan melalui Picture and Picture

Berdasarkan latar belakang tersebut diatas peneliti tertarik untuk melakukan Penelitian Tindakan Kelas pada pembelajaran PAI dengan mengangkat judul "Pengajaran Shalat Fardhu Melalui Model Pembelajaran Picture and Picture untuk meningkatkan Hasil Belajar Pada Siswa Kelas III SDN 011 Balikpapan Timur Tahun Pelajaran 2019/2020.

\section{METODE PENELITIAN}

Penelitan tindakan kelas ini menggunakan desain penelitian yang digunakan adalah model dari Kemmis dan Taggart berupa suatu siklus spiral. Pengertian siklus disini adalah suatu putaran kegiatan yang meliputi tahapan-tahapan rancangan pada setiap putarannya, yaitu: (1) perencanaan (planning), (2) tindakan (acting), (3) observasi (observation), (4) refleksi (reflection). Desain penelitian berupa gambar yang tahapannya menggunakan prosedur kerja Kemmis dan Mc Taggart.

\section{HASIL DAN PEMBAHASAN}

\section{Hasil}

\section{Deskripsi Hasil Siklus I}

Pada Siklus I dimulai dengan tahapan perencanaan adapun yang dilaksanakan dalam pertemuan 1 adalah peneliti membuat rencana persiapan pembelajaran, media pembelajaran, lembar kerja siswa dan lembar pengamatan siswa yang sesuai dengan 
materi pembelajaran untuk pertemuan pertama, materi yang disajikan pada rencana pelaksanaan pembelajaran pada lampiran

\section{a. Tahap Perencanaan}

Adapun langkah-langkah yang dilakukan dalam proses persiapan pembelajaran adalah sebagai berikut :

1) Memilih pokok bahasan atau indikator yang sesuai dengan shalat fardhu . Indikator yang tepat untuk siklus I adalah memperagakan gerakan shalat

2) Menyusun rencana pembelajaran berdasarkan indikator yang telah dibuat.Rencana pembelajaran yang disusun oleh peneliti memuat 1 kali pertemuan, dalam waktu 2 jam pelajaran dilaksanakan dalam 1 minggu. Mengenai langkah-langkah dan susunan rencana pembelajaran terlampir.

3) Menyiapkan model pembelajaran picture and picture yang akan digunakan dalam pembelajaran. Pada siklus I guru menggunakan model pembelajaran picture and gambar tata cara gerakan shalat. Pada siklus I ini, guru menggunakan gambar dengan meminta kepada siswa untuk menjelaskan maksud dari gambar tersebut untuk menjelaskan sehingga tanpa melihat gambar sudah tau apa maksud dari gerakan tersebut tersebut.

\section{b. Tahap Tindakan}

Dalam tahap ini guru menerapkan pembelajaran dengan menggunakan model pembelajaran picture and picture sesuai dengan rencana pembelajaran yang telah disusun. Pembelajaran yang telah disusun pada siklus I dengan menggunakan model pembelajaran picture and picture ini dilaksanakan dalam 1 kali pertemuan. Adapun model pembelajaran picture and yang pada pertemuan pada siklus I.

\section{c. Tahap Observasi}

Sesuai dengan tujuan penelitian yaitu dalam rangka meningkatkan kemampuan shalat fardhu siswa dalam pembelajaran PAI , hasil observasi untuk guru dan siswa, nilai tes siklus I adalah sebagai berikut :

Tabel 1. Nilai Tes Siswa Siklus I

\begin{tabular}{|c|c|c|c|c|c|}
\hline \multirow{2}{*}{ No } & \multirow{2}{*}{ Nama Siswa } & \multirow{2}{*}{ KKM } & \multirow{2}{*}{ Nilai } & \multicolumn{2}{|c|}{ Keterangan } \\
\hline & & & & Tuntas & Tidak Tuntas \\
\hline 1 & ADE MAWAN & 78 & 85 & Tuntas & \\
\hline 2 & ARSHIP IBNU & 78 & 80 & Tuntas & \\
\hline 3 & AQILA NUR NAJWA & 78 & 78 & Tuntas & \\
\hline 4 & ATIKAH SALSABILA & 78 & 65 & & Tidak Tuntas \\
\hline 5 & AZZAKIYAH & 78 & 82 & Tuntas & \\
\hline 6 & FIDA MAHARANI & 78 & 84 & Tuntas & \\
\hline 7 & INDRI AJI & 78 & 85 & Tuntas & \\
\hline 8 & MALVI DWI & 78 & 55 & & Tidak Tuntas \\
\hline 9 & MARVIN & 78 & 60 & & Tidak Tuntas \\
\hline 10 & M. AWAL & 78 & 78 & Tuntas & \\
\hline 11 & M. FAHRY & 78 & 78 & Tuntas & \\
\hline 12 & M. HAS BIMA & 78 & 80 & Tuntas & \\
\hline 13 & M. RIZQULLAH & 78 & 85 & Tuntas & \\
\hline 14 & MULYANA & 78 & 65 & & Tidak Tuntas \\
\hline 15 & NADILA ELMA & 78 & 65 & & Tidak Tuntas \\
\hline 16 & NAZIFA & 78 & 78 & Tuntas & \\
\hline 17 & NUR AZIZAH & 78 & 80 & Tuntas & Tidak Tuntas \\
\hline 18 & RIZKY P & 78 & 65 & & Tidak Tuntas \\
\hline 19 & SINTA R & 78 & 80 & Tuntas & \\
\hline 20 & SIVA AULIA & 78 & 65 & & Tidak Tuntas \\
\hline 21 & ZAHIRA & 78 & 70 & & \\
\hline 22 & RISMA & 78 & 65 & Tuntas & \\
\hline 23 & M. ARYA EVAN & 78 & 78 & Tuntas & \\
\hline & Jumlah & & 1622 & 15 & 8 \\
\hline
\end{tabular}




\begin{tabular}{|c|c|c|c|c|}
\hline Rata-rata & & 74,17 & & \\
\hline Prosentase Ketuntasan (\%) & & & 60,00 & 40,00 \\
\hline Nilai Tertinggi & & 85 & & \\
\hline Nilai Terendah & & 65 & & \\
\hline
\end{tabular}

Berdasarkan tabel 1 ketuntasan belajar siswa pada siklus I dapat digambarkan pada grafik sebagai berikut:

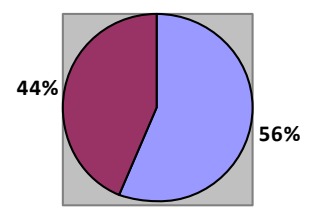

\section{Gambar 1. Persentase Ketuntasan belajar siswa siklus I}

Setelah dilaksanakan Penelitian Tindakan Kelas pada siklus 1 selesai maka dapat diketahui adanya kenaikan hasil belajar siswa dari perolehan nilai sebelumnya (pra siklus).

Dari hasi nilai evaluasi pada Pra Siklus, masih banyak siswa yang nilainya belum mencapai Keriteria Ketuntasan Minimal (KKM), KKM yang ditargetkan adalah 78. Dari 23 orang siswa terdapat 14 orang siswa yang nilainya belum mencapai KKM, jika dipersentasikan jumlah siswa yang nilainya mencapai KKM adalah 30\%. Setelah diadakan pada Penelitian Tindakan Kelas pada siklus 1, ternyata ada peningkatan yaitu menjadi 8 orang siswa yang nilainya belum mencapai KKM. Jika dipersentasekan jumlah siswa yang mencapai KKM pada siklus I adalah $60 \%$. Maka kenaikan persentase dari nilai evaluasi pra siklus ke siklus 1 yaitu $15 \%$.Ini membuktikan ada peningkatan nilai siswa antar Pra Siklus dan Siklus1.

Adapun hasil perolehan nilai hasil evaluasi pada pembelajaran Pra Siklus, dan Siklus 1 adalah sebagai berikut :

Tabel 2. Perolehan Nilai Evaluasi Pra Siklus dan Siklus 1

\begin{tabular}{|c|l|c|c|}
\hline \multirow{2}{*}{ No } & \multicolumn{1}{|c|}{ Nama Siswa } & \multicolumn{2}{|c|}{ Nilai } \\
\cline { 3 - 4 } 1 & & Pra siklus & Siklus I \\
\hline 2 & ADE MAWAN & 75 & 85 \\
3 & ARSHIP IBNU & 70 & 80 \\
4 & ATIKAH SALSABILA & 60 & 65 \\
5 & AZZAKIYAH & 65 & 82 \\
6 & FIDA MAHARANI & 72 & 84 \\
7 & INDRI AJI & 80 & 85 \\
8 & MALVI DWI & 50 & 55 \\
9 & MARVIN & 55 & 60 \\
10 & M. AWAL & 65 & 78 \\
11 & M. FAHRY & 65 & 78 \\
12 & M. HAS BIMA & 70 & 80 \\
13 & M. RIZQULLAH & 80 & 85
\end{tabular}




\begin{tabular}{|l|l|c|c|}
14 & MULYANA & 60 & 65 \\
15 & NADILA ELMA & 60 & 65 \\
16 & NAZIFA & 70 & 78 \\
17 & NUR AZIZAH & 75 & 80 \\
18 & RIZKY P & 60 & 65 \\
19 & SINTA R & 70 & 80 \\
20 & SIVA AULIA & 60 & 65 \\
21 & ZAHIRA & 70 & 70 \\
22 & RISMA & 60 & 65 \\
23 & M. ARYA EVAN & 70 & 78 \\
\hline \multicolumn{2}{|c|}{ Jumlah } & 1327 & 1622 \\
\hline \multicolumn{2}{|c|}{ Rata-rata } & 66,35 & 74,17 \\
\hline \multicolumn{2}{|c|}{ Prosentase Ketuntasan $(\%)$} & 45,00 & 60,00 \\
\hline \multicolumn{2}{|c|}{ Nilai Tertinggi } & 80 & 85 \\
\hline \multicolumn{2}{|c|}{ Nilai Terendah } & 50 & 65 \\
\hline
\end{tabular}

Berdasarkan tabel 2 perbandingan perolehan nilai siswa Pra siklus dan siklus I secara terperinci dapat digambarkan pada grafik sebagai berikut:

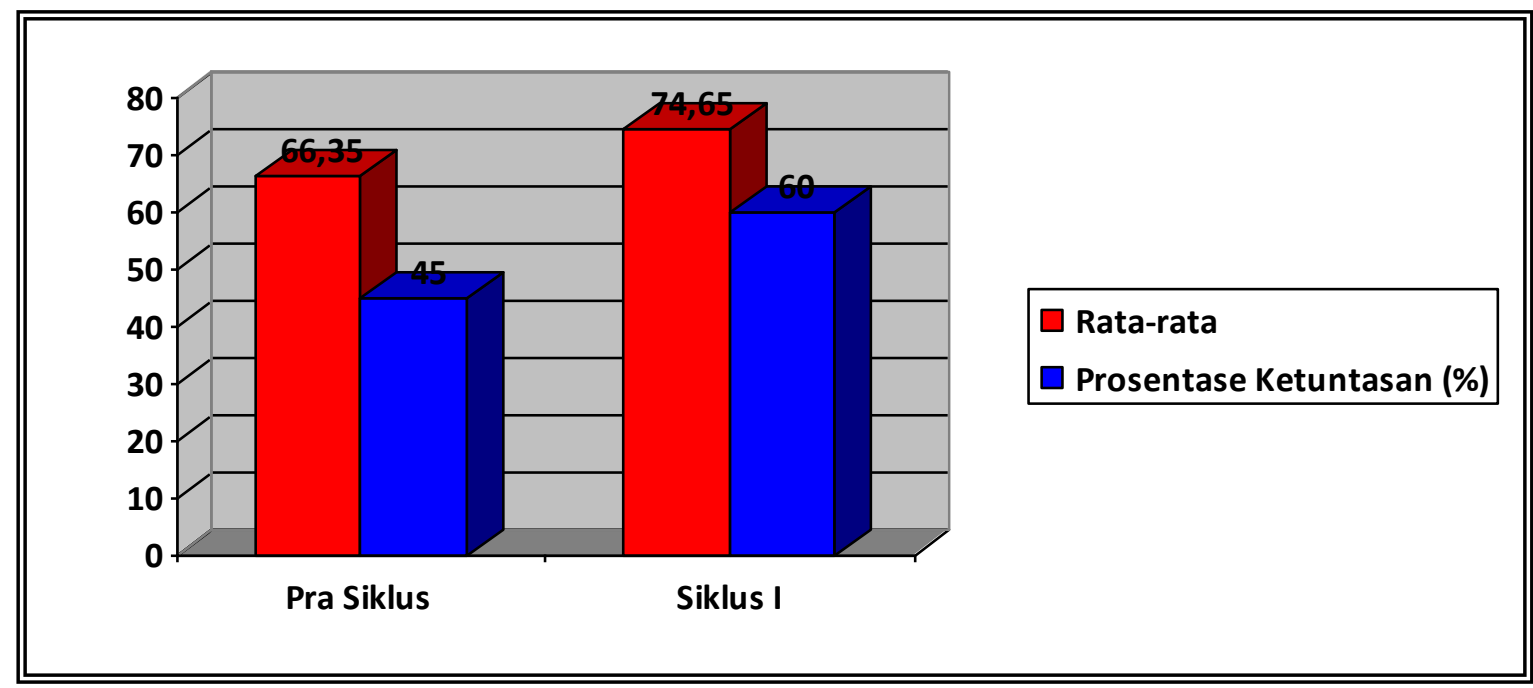

Gambar 2. Grafik Perolehan Nilai Evaluasi pada Pra Siklus, Siklus 1

\section{d. Refleksi Siklus I}

Berdasarkan kumpulan data yang diperoleh dari kolaborasi dengan teman sejawat serta hasil observasi, tugas dan tes yang ada pada peneliti, ternyata presentase nilai hasil belajar siswa belum memenuhi standar hasil belajar minimal yang ditetapkan oleh SDN 011 Balikpapan Timur yaitu dilihat dari nilai siswa yang mencapai 78 atau lebih presentase siswa belum mencapai $85 \%$ seperti yang terlihat pada table 4.2 . Hal ini menunjukkan bahwa tujuan yang hendak dicapai sehubungan dengan pelaksanaan tindakan ini belum tercapai.

\section{Deskripsi Hasil Siklus II}

a. Perencanaan Tindakan

Berdasarkan hasil refleksi dan evaluasi pelaksanaan tindakan pada siklus II diketahui bahwa beberapa siswa belum menunjukkan adanya peningkatan prestasi belajar yang memuaskan. Ada beberapa indikator shalat fardhu yang tidak dipenuhi siswa yaitu siswa belum mampu memperagakan posisi yang benar sesuai dengan gambar sehingga sebagaian siswa belum menunjukkan peningkatan prestasi belajar yang diinginkan. 


\section{b. Tahap Tindakan}

Peneliti bertindak sebagai guru yang melaksanakan kegiatan belajar mengajar sesuai dengan rencana persiapan pembelajaran pada lampiran selain sesuai dengan rencana persiapan pembelajaran yang telah disusun, peneliti juga menjalankan hasil refleksi siklus I, hal ini dilaksanakan untuk mengadakan perbaikan dalam proses belajar mengajar.

\section{c. Tahap Observasi}

Pada tahap ini dilaksanakan observasi terhadap pelaksanaan tindakan yaitu dengan mengamati setiap tindakan yang dilaksanakan meliputi aktifitas yang dilakukan guru dengan murid, interaksi guru dengan murid, interaksi muriddengan murid, semua kegiatan pembelajaran yang sedang berlangsung. Berdasarkan saran dari pembimbing dan teman sejawat diperoleh hasil tes siklus II sebagai berikut:

Tabel 3. Nilai Tes Siswa Siklus II

\begin{tabular}{|c|c|c|c|c|c|}
\hline \multirow{2}{*}{ No } & \multirow{2}{*}{ Nama Siswa } & \multirow{2}{*}{ KKM } & \multirow{2}{*}{ Nilai } & \multicolumn{2}{|c|}{ Keterangan } \\
\hline & & & & Tuntas & Tidak Tuntas \\
\hline 1 & ADE MAWAN & 78 & 95 & Tuntas & \multirow{23}{*}{$\begin{array}{l}\text { Tidak Tuntas } \\
\text { Tidak Tuntas }\end{array}$} \\
\hline 2 & ARSHIP IBNU & 78 & 90 & Tuntas & \\
\hline 3 & AQILA NUR NAJWA & 78 & 85 & Tuntas & \\
\hline 4 & ATIKAH SALSABILA & 78 & 80 & Tuntas & \\
\hline 5 & AZZAKIYAH & 78 & 85 & Tuntas & \\
\hline 6 & FIDA MAHARANI & 78 & 92 & Tuntas & \\
\hline 7 & INDRI AJI & 78 & 90 & Tuntas & \\
\hline 8 & MALVI DWI & 78 & 60 & & \\
\hline 9 & MARVIN & 78 & 65 & & \\
\hline 10 & M. AWAL & 78 & 85 & Tuntas & \\
\hline 11 & M. FAHRY & 78 & 85 & Tuntas & \\
\hline 12 & M. HAS BIMA & 78 & 90 & Tuntas & \\
\hline 13 & M. RIZQULLAH & 78 & 90 & Tuntas & \\
\hline 14 & MULYANA & 78 & 80 & Tuntas & \\
\hline 15 & NADILA ELMA & 78 & 80 & Tuntas & \\
\hline 16 & NAZIFA & 78 & 80 & Tuntas & \\
\hline 17 & NUR AZIZAH & 78 & 85 & Tuntas & \\
\hline 18 & RIZKY P & 78 & 80 & Tuntas & \\
\hline 19 & SINTA R & 78 & 80 & Tuntas & \\
\hline 20 & SIVA AULIA & 78 & 80 & Tuntas & \\
\hline 21 & ZAHIRA & 78 & 85 & Tuntas & \\
\hline 22 & RISMA & 78 & 85 & Tuntas & \\
\hline 23 & M. ARYA EVAN & 78 & 90 & Tuntas & \\
\hline & Jumlah & & 1657 & 18 & 2 \\
\hline & Rata-rata & & 82,85 & & \\
\hline & sentase Ketuntasan (\%) & & & 90,00 & 10,00 \\
\hline & Nilai Tertinggi & & 90 & & \\
\hline & Nilai Terendah & & 60 & & \\
\hline
\end{tabular}

Berdasarkan tabel 3 tentang hasil penelitian siklus II,ketuntasan belajar siswa pada siklus I dapat digambarkan pada garif sebagai berikut:

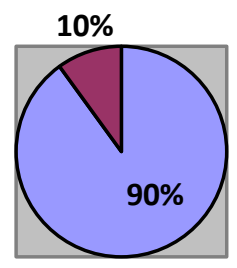


Adapun perolehan nilai evaluasi pada siklus 1 yang dibandingkan dengan perolehan nilai evaluasi siklus 2, dapat dilihat pada tabel di bawah ini

Tabel 4. Perolehan Nilai Evaluasi Siklus 1 dan Siklus 2

\begin{tabular}{|c|c|c|c|}
\hline \multirow{2}{*}{ No } & \multirow{2}{*}{ Nama Siswa } & \multicolumn{2}{|c|}{ Nilai } \\
\hline & & Siklus I & Siklus II \\
\hline 1 & ADE MAWAN & 85 & 95 \\
\hline 2 & ARSHIP IBNU & 80 & 90 \\
\hline 3 & AQILA NUR NAJWA & 78 & 85 \\
\hline 4 & ATIKAH SALSABILA & 65 & 80 \\
\hline 5 & AZZAKIYAH & 82 & 85 \\
\hline 6 & FIDA MAHARANI & 84 & 92 \\
\hline 7 & INDRI AJI & 85 & 90 \\
\hline 8 & MALVI DWI & 55 & 70 \\
\hline 9 & MARVIN & 60 & 70 \\
\hline 10 & M. AWAL & 78 & 85 \\
\hline 11 & M. FAHRY & 78 & 85 \\
\hline 12 & M. HAS BIMA & 80 & 90 \\
\hline 13 & M. RIZQULLAH & 85 & 90 \\
\hline 14 & MULYANA & 65 & 80 \\
\hline 15 & NADILA ELMA & 65 & 80 \\
\hline 16 & NAZIFA & 78 & 80 \\
\hline 17 & NUR AZIZAH & 80 & 85 \\
\hline 18 & RIZKY P & 65 & 80 \\
\hline 19 & SINTA R & 80 & 80 \\
\hline 20 & SIVA AULIA & 65 & 80 \\
\hline 21 & ZAHIRA & 70 & 85 \\
\hline 22 & RISMA & 65 & 85 \\
\hline 23 & M. ARYA EVAN & 78 & 90 \\
\hline & Jumlah & 1622 & 1927 \\
\hline & Rata-rata & 74,65 & 83,34 \\
\hline & sentase Ketuntasan (\%) & 60,00 & 90,00 \\
\hline & Nilai Tertinggi & 85 & 90 \\
\hline & Nilai Terendah & 65 & 70 \\
\hline
\end{tabular}

Berdasarkan tabel 4perbandingan peroleh nilai siswa siklus I dan siklus II dapat digambarkan pada grafik sebagai berikut 


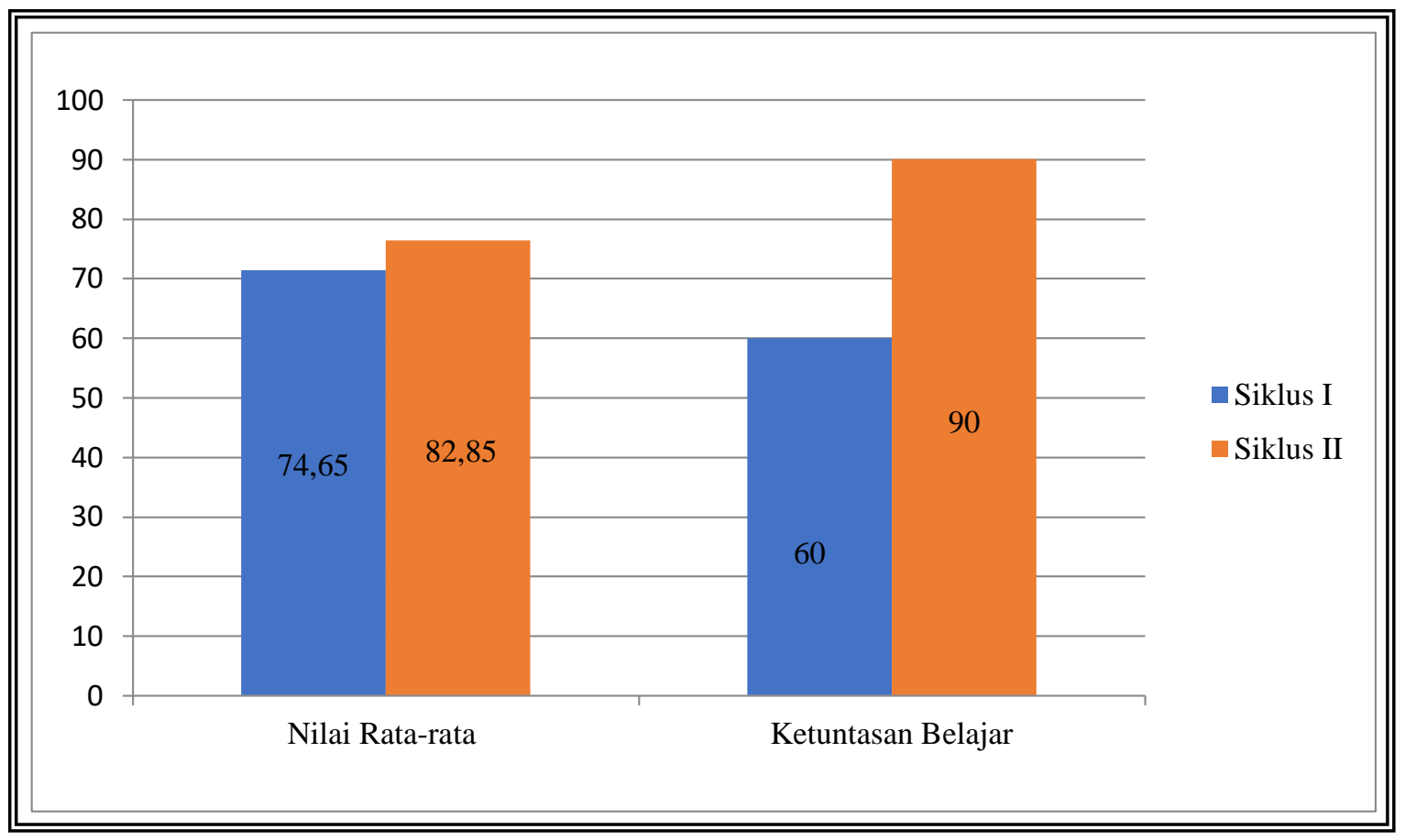

\section{Gambar 4. Perolehan Nilai Evaluasi pada Siklus 1 dan 2}

Adapun perbandingan perolehan nilai evaluasi mulai dari pra siklus, siklus 1, siklus 2 dapat dilihat dari tabel di bawah ini.

Tabel 5 Rekapitulasi Perolehan Nilai Evaluasi pada Pra Siklus, Siklus 1 dan 2

\begin{tabular}{|c|c|c|c|c|}
\hline \multirow{2}{*}{ No } & \multirow{2}{*}{ Nama Siswa } & \multicolumn{3}{|c|}{ Nilai } \\
\hline & & Pra Siklus & Siklus I & Siklus II \\
\hline 1 & ADE MAWAN & 75 & 85 & 95 \\
\hline 2 & ARSHIP IBNU & 70 & 80 & 90 \\
\hline 3 & AQILA NUR NAJWA & 65 & 78 & 85 \\
\hline 4 & ATIKAH SALSABILA & 60 & 65 & 80 \\
\hline 5 & AZZAKIYAH & 65 & 82 & 85 \\
\hline 6 & FIDA MAHARANI & 72 & 84 & 92 \\
\hline 7 & INDRI AJI & 80 & 85 & 90 \\
\hline 8 & MALVI DWI & 50 & 55 & 70 \\
\hline 9 & MARVIN & 55 & 60 & 70 \\
\hline 10 & M. AWAL & 65 & 78 & 85 \\
\hline 11 & M. FAHRY & 65 & 78 & 85 \\
\hline 12 & M. HAS BIMA & 70 & 80 & 90 \\
\hline 13 & M. RIZQULLAH & 80 & 85 & 90 \\
\hline 14 & MULYANA & 60 & 65 & 80 \\
\hline 15 & NADILA ELMA & 60 & 65 & 80 \\
\hline 16 & NAZIFA & 70 & 78 & 80 \\
\hline 17 & NUR AZIZAH & 75 & 80 & 85 \\
\hline 18 & RIZKY P & 60 & 65 & 80 \\
\hline 19 & SINTA R & 70 & 80 & 80 \\
\hline 20 & SIVA AULIA & 60 & 65 & 80 \\
\hline
\end{tabular}




\begin{tabular}{|l|l|c|c|c|}
21 & ZAHIRA & 70 & 70 & 85 \\
22 & RISMA & 60 & 65 & 85 \\
23 & M. ARYA EVAN & 70 & 78 & 90 \\
\hline \multicolumn{2}{|c|}{ Jumlah } & 1327 & 1622 & 1927 \\
\hline \multicolumn{2}{|c|}{ Rata-rata } & 66,35 & 74,65 & 83,34 \\
\hline Prosentase Ketuntasan (\%) & 45,00 & 60,00 & 90,00 \\
\hline \multicolumn{2}{|c|}{ Nilai Tertinggi } & 80 & 85 & 90 \\
\hline Nilai Terendah & 50 & 65 & 70 \\
\hline
\end{tabular}

Secara keseluruhan nilai rata-rata siklus 1 dan 2 sudah menunjukan keberhasilan dari penggunaan model pembelajaran picture and picture dalam meningkatkan hasil belajar siswa dengan ketuntasan belajar mencapai $90 \%$ atau hanya 2 siswa yang belum tuntas dari 23 orang siswa, secara terperinci tergambar pada grafik-grafik sebagai berikut

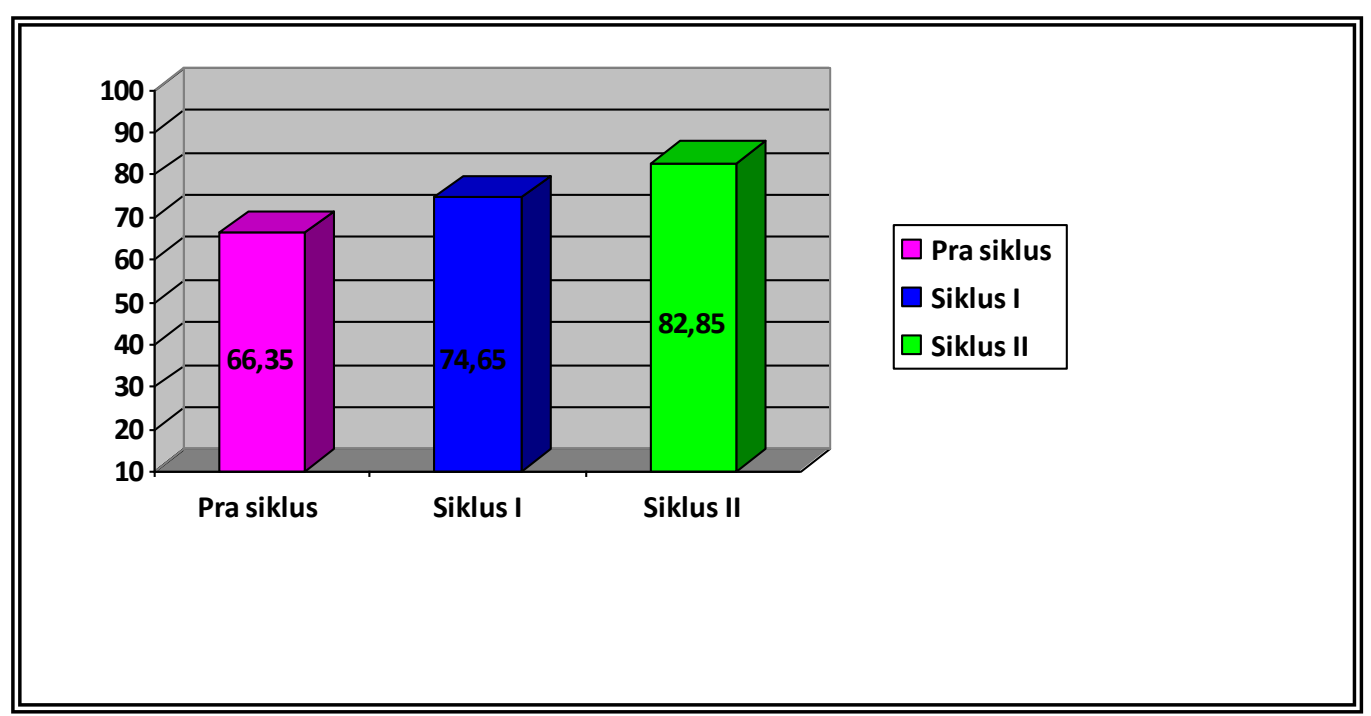

Gambar 5. Grafik Perolehan Nilai Evaluasi pada Pra Siklus, Siklus 1dan 2

Ketuntasan Hasil belajar siswa secara keseluruhan selama melaksanakan tindakan penelitian perbaikan hasil belajar PAI dapat terlihat pada gambar grafik sebagai berikut:

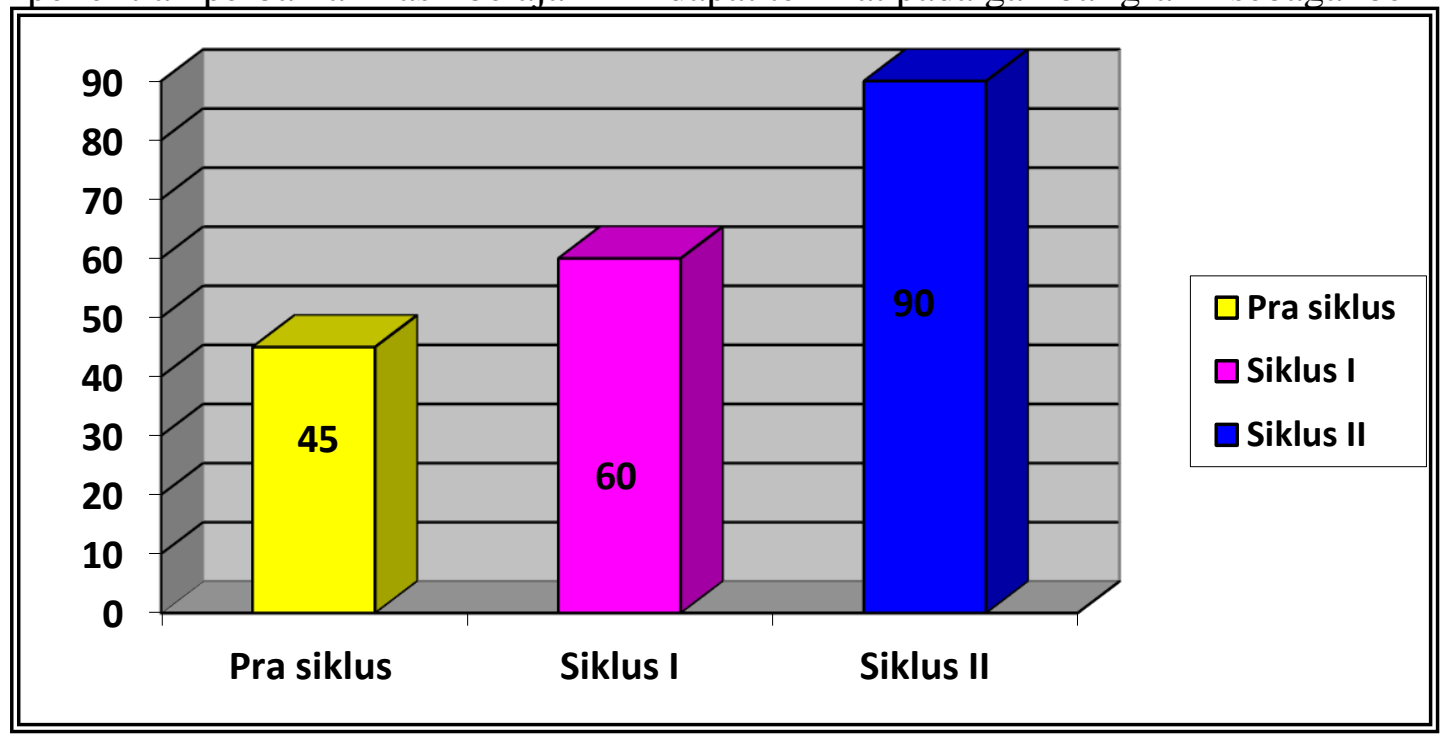

Gambar 6. Grafik Persentase Pencapaian KKM Pra Siklus, Siklus 1, Siklus 2 


\section{Pembahasan}

\section{Pembahasan Siklus I}

Adapun hal-hal yang menyebabkan keberhasilan penggunaan model pembelajaran picture and picture pada siklus I adalah mengacu pada prinsip prinsip sebagai berikut:

a. Menggunakan gambar untuk tujuan pelajaran spesifik, yaitu dengan cara memilih gambar yang akan mendukung penjelasan inti. Tujuan khusus itulah yang mengarahkan minat siswa kepada pokok penting dalam pelajaran. Menggunakan gambar dengan tepat maka akan efektif mencapai keberhasilan. Gambar sangat penting untuk mengembangkan pemahaman atau gagasan baru.

b. Guru yang baik akan menyadari dengan mengurangi deskripsi verbal kepada gambargambar yang dipertunjukkan akan dirasakan manfaat lebih besar. Model pembelajaran picture and picture dapat memberikan manfaat merangsang minat dan perhatian anak, membantu anak memahami dan mengingat isi informasi verbal yang ada. Dengan gambar lebih efektif sebagai penyampai informasi. Gambar dengan warna yang bermacam-macam akan menarik bagi anak. Gambar yang efektif bagi anak umumnya enak dipandang, dan mudah dimengerti maksudnya.

c. Gambar yang digunakan dalam penelitian ini berupa gambar benda-benda yang ada di sekitar anak yang sering dijumpai dalam kehidupan sehari-hari. Dengan harapan akan lebih memudahkan anak mengerti nama mengurangi verbalisme dalam menerima materi pelajaran.

\section{Pembahasan Siklus II}

Pelaksanaan program tindakan II yang mengacu pada identifikasi masalah yang muncul pada siklus I, sesuai dengan alternatif pemecahan masalah yang sudah ditentukan, antara lain melalui:

a. Guru melakukan apersepsi

b. Siswa yang diperkenalkan dengan materi yang akan dibahas dan tujuan yang ingin dicapai dalam pembelajaran.

c. Guru membuat model pembelajaran picture and picture dengan warna w/arni

d. Siswa menceritakan isi yang tertulis pada gambar dan menyampaika temanya di depan kelas

e. Siswa memilih gambar sesuai dengan keinginan siswa.

\section{PENUTUP}

Berdasarkan uraian pada hasil penelitian dan pembahasan, maka dapat disimpulkan bahwa model pembelajaran picture and picture dapat meningkatkan hasil belajar tentang shalat fardhu pada siswa kelas III SDN 029 Balikpapan Tengah. Hal tersebut tampak pada peningkatan kemampuan shalat fardhu siswa pada setiap siklus. yaitu dari pra siklus dengan rata-rata 66,35 meningkat menjadi 74,65 pada siklus I kemudian pada siklus II nilai rata-rata hasil belajar siswa meningkat menjadi 82,85, begitupun persentase ketuntasan belajar meningkat dari pra siklus yang hanya $45 \%$ menjadi $60 \%$ pada siklus I, kemudian siklus II menjadi $90 \%$ siswa.

\section{DAFTAR PUSTAKA}

Abdul Majid. (2008). Perencanaan Pembelajaran. Bandung: PT Remaja

Aqih, Zaenal. (2004). Profesionalisme Guru Dalam Pembelajaran. Cendikia. Bandung.

Arief S. Sadiman. (2003). Media Pendidikan. Jakarta: Rajawali

Arikunto, Suharsimi, (2002). Prosedur Penelitian, Suatu Pendekatan Praktek. Jakarta: PT.Rineka Cipta

Arsyad, Azwar. (2003). Media Pembelajaran. Jakarta : Raja Grafindo Persada

Depdiknas. (2006). Panduan Kurikulum Tingkat Satuan Pendidikan (KTSP) SD/MI. Jakarta : BP. Dharma Bhakti Jakarta 
Dimyati, Mudjiono. (2003). Belajar dan Pembelajaran. Rineka Cipta. Jakarta.

Hamalik, O. (2003). Kurikulum dan Pembelajaran. Bumi aksara. Jakarta.

Istarani (2011). Model Pembelajaran Inovatif (Referensi Guru Dalam Menentukan Model Pembelajaran). (Medan: Media Persada, 2011)

Mohammad Ali (2007). Modul Teori dan Praktek Pembelajaran Pendidikan Dasar, (Bandung: UPI Press)

Nasution, (2000). Berbagai Pendekatan Dalam Proses Belajar Mengajar. Bumi Aksara. Bandung.

Poerwodarminto. (1976). Kamus Umum PAI . Balai Pustaka.Jakarta.

Putrayasa, Ida Bagus. (2008). Kajian Morfologi Bentuk Derivasi dan Infleksional. Bandung: Refika Aditama

Ramlan, M. (1978). Morfologi Suatu Tinjauan Deskriptif. Yogyakarta: U.B. Karyanto Rosdakarya.

Sanjaya,W. (2006). Strategi Pembelajaran.Jakarta: Kencana Prenada Media 